\title{
Corrigendum
}

\section{Changes in socio-economic differences in food habits over time - CORRIGENDUM}

\author{
Tina Seiluri, Eero Lahelma, Ossi Rahkonen and Tea Lallukka
}

First published online 13 January 2015

doi:10.1017/S1368980011000681, published online by Cambridge University Press 4 May 2011

Our paper ${ }^{1}$ mistakenly calls the inequality index described in the Statistical analyses the Slope Index of Inequality (SII). The index used is the Relative Index of Inequality (RII), which measures the magnitude of relative occupational class differences in the studied food habits. Absolute differences mentioned in the paper only refer to prevalence differences between occupational classes in Tables 2 and 3. The error does not affect the results reported or their interpretation.

\section{Reference}

Seiluri T, Lahelma E, Rahkonen O \& Lallukka T (2011) Changes in socio-economic differences in food habits over time. Public Health Nutr 14, 1919-1926. 